\title{
A fé como um dos elementos no processo de formação de professoras-estudantes do PARFOR
}

\author{
Faith as one of the elements in the formation process of female teachers-students of \\ PARFOR
}

\begin{abstract}
Resumo
Esta pesquisa explicita seu bojo, algumas reflexões acerca da fé como um dos elementos no processo de formação de professoras-estudantes do PARFOR. A formação de professores no Brasil tem impresso uma marca vincada no currículo e em aspectos cognitivos que reverberam sobre a profissão docente. Sabe-se que a trajetória de formação envolve movimentos dialógicos para além da cognição e do currículo, sobretudo, questões que envolvem a movimentos internos do próprio sujeito. Com efeito, o presente trabalho revela alguns resultados de uma pesquisa qualitativa do tipo estudo de casos múltiplos que adotou a entrevista narrativa e o mapa do self como dispositivos de coleta das informações de dez professoras-estudantes do curso de Pedagogia promovido pelo PARFOR no município de Serrinha-BA. O estudo revelou que a fé consiste em mola impulsionadora do selves de professoras-estudantes durante a formação, sobretudo durante os momentos de apoio e não-apoio vivenciado no processo formativo.
\end{abstract}

\section{Palavras-chave}

Formação no PARFOR. Professoras-estudantes. Fé.

\begin{abstract}
This research explains in its base, some reflections about faith as one of the elements in the formation process of female teachers-students of PARFOR. The formation of teachers in Brazil has stamped an emphatic mark on the
\end{abstract}

[Texto recebido em janeiro de 2018 e aceito em janeiro de 2018, com base na avaliação cega por pares realizada por pareceristas ad hoc]

* Licenciada em Pedagogia. Especialista em Avaliação e em Educação Infantil. Mestre em Educação e Contemporaneidade. Doutora em Família na Sociedade Contemporânea. Pós-Doutoranda em Educação e Contemporaneidade (PPGEduC/UNEB). Líder do Grupo de pesquisa EPODS. Professora Adjunta da Universidade do Estado da Bahia/Campus XI, Serrinha, Bahia - Brasil. E-mail: ivoneteeducadora@hotmail.com

** Graduada em Psicologia. Mestre em Psicologia Experimental (USP). Doutora em Psicologia Social (USP). Pós-Doutora pela USP. Líder do Grupo de Pesquisa Família, (auto)biografia e poética-FABEP/UCSAL. Professora do Programa de Pós-Graduação em Família na Sociedade Contemporânea-UCSAL, Salvador, Bahia- Brasil. Email: elainepedreira@gmail.com 


\begin{abstract}
curriculum and on cognitive aspects which reverberate on the teaching profession. It is known that the formation trajectory involves dialogical movements beyond cognition and curriculum, above all, issues which involve internal movements of the subject herself. In effect, this paper reveals some results of a qualitative research of a multiple case study type which adopted the narrative interview and self-map as tools for collecting information from ten female teachers-students of the Pedagogy program promoted by PARFOR in the municipality of Serrinha-BA. The study revealed that faith is a propelling spring of the selves of female teachersstudents during the formation, especially during the moments of support and of non-support experienced in the formative process.
\end{abstract}

\title{
Keywords
}

Formation at PARFOR. Female teachers-students. Faith.

\section{Introdução}

O processo de formação docente no contexto de Ensino Superior brasileiro apresenta diferentes formatos, os quais variam do tipo de instituição até a modalidade do curso. Com efeito, a Lei de Diretrizes e Bases da Educação Nacional (LDBEN n. 9.394/96) assevera no Art. 45 que “a educação superior será ministrada em instituições de ensino superior público ou privado, com variados graus de abrangência ou especialização". ${ }^{1}$ Dentro dessa organização, os cursos podem ter oferta contínua, oferta especial na modalidade de educação presencial e à distância. Tendo como base que este artigo tem como objetivo explicitar a fé com um dos elementos no processo de formação de professoras-estudantes do Plano Nacional de Formação de Professores da Educação Básica (PARFOR), revelaremos, incialmente, algumas peculiaridades dessa formação.

Destaca-se que o PARFOR consiste em um programa do Governo Federal que, segundo a Coordenação de Aperfeiçoamento de Pessoal de Nível Superior (CAPES), tem como principal objetivo induzir e fomentar a oferta de educação superior, gratuita e de qualidade, para professores em exercício na rede pública de educação básica, para que estes profissionais possam obter a formação exigida pela LDB e contribuam para a melhoria da qualidade da educação básica no país. ${ }^{2}$

Com base nessa perspectiva, este Plano representa uma oportunidade para que professores e professoras, no exercício do magistério público, possam, através de cursos de licenciaturas em Instituições Públicas de Ensino Superior, efetivar formação para melhorar sua atuação. Essa ação intenta atender às demandas de formação docente em território nacional, a qual encontra-se ancorada no que diz o Decreto n. 6.755, de 29 de janeiro de 2009, quando no seu Art. 11, Inciso III, destaca que a CAPES fomentará oferta emergencial

1 BRASIL. Ministério da Educação. Lei n. 9.394, de 20 de dezembro de 1996. Estabelece as Diretrizes e Bases da Educação Nacional. Brasília: MEC, 1996.

2 BRASIL. Coordenação de Aperfeiçoamento de Pessoal de Nível Superior. Plano Nacional de Formação de Professores da Educação Básica - PARFOR. Disponível em: <http://www.capes.gov.br/educacaobasica/parfor>. Acesso em: 07 dez. 2016. 
de cursos de licenciaturas e de cursos ou programas especiais dirigidos aos docentes em exercício há pelo menos três anos na rede pública de educação básica, que sejam: a) graduados não licenciados; b) licenciados em área diversa da atuação docente; e c) de nível médio, na modalidade Normal. ${ }^{3}$

Com efeito, justifica-se o termo "professoras-estudantes", destinado às colaboradoras desta pesquisa, ancorado na condição objetiva a que essas mulheres são impostas para participarem da formação do PARFOR, pois precisam estar em sala de aula exercendo a profissão docente para ser estudante na referida licenciatura, assim como exercer o papel de mãe, esposa. Outrossim, é oportuno destacar que a permanência das colaboradoras no referido programa trouxe à tona a dimensão da fé como uma das molas propulsora no âmbito da formação, emersão que nos possibilitou trazer as questões deste artigo.

Assim, a fé aparece como elemento impulsionador da formação. Neste sentido, é nevrálgico sinalizar que a fé consiste em uma dimensão pessoal e intransferível de cada colaboradora da pesquisa diante da formação docente no PARFOR. Explicitam, ainda, que a fé está amparada em uma forte confiança em Deus, como foi constatado nas falas das estudantes-professoras, pois elas não duvidam que ao crer em Deus ganharam força para enfrentamento dos obstáculos durante o Curso de Pedagogia no PARFOR. Em outras palavras, como afirma Amatuzzi, "todos nós temos uma fé que é aquilo que dá sabor a nossa existência. É a aposta de cada um, que o faz viver. Dizer que o ser humano precisa de significação é dizer que ele constrói uma fé". ${ }^{4}$ E realmente a fé referendada ganhou eco nas vozes internas de reforço à permanência na formação.

Ademais, o referido estudo encontra-se ancorado na pesquisa qualitativa, do tipo estudo de casos múltiplos, o qual teve como dispositivos coleta de informações, o mapa dos self5 e a entrevista narrativa, com dez professoras-estudantes da Licenciatura em Pedagogia do PARFOR. Em tempo, é relevante destacar que este artigo é parte da tese de doutorado apresentada no Programa de Pós-Graduação em Família na Sociedade Contemporânea da Universidade Católica do Salvador (UCSAL). ${ }^{6}$ Diante deste cenário introdutório, este estudo foi organizado em três seções: a primeira, consta desta

3 BRASIL. Decreto n. 6.755, de 19 de janeiro de 2009. Institui a Política Nacional de Formação dos Profissionais do Magistério e regulamenta a ação da CAPES. Brasília, 2009.

4 AMATUZZI, Mauro Martins. Fé e Ideologia na Compreensão Psicológica da Pessoa. Psicologia: Reflexão e Crítica, v. 16, n. 3, p. 569-575, 2003. à p. 570.

5 O mapa do self dialógico consiste em um método baseado na Family Circles Method (FCM) que permite aos participantes da pesquisa produzir uma representação das suas vidas pessoais, os limites e espaço, parentes próximos e a distância dos relacionamentos. CHAUDHARY, Nandita; SHARMA, Neerja. Mapping the self and the family. In: ANANDALAKSHAMY, S.; CHAUDHARY, Nandita; SHARMA, Neerja (Orgs.). Researching families and children: culturally appropriate methods. Dehli: Sage, 2008.

6 AMORIM, Ivonete Barreto de. Entre casulo e asa: diálogos e movimentos dos selves de professorasestudantes no contexto da formação no PARFOR. Tese (Doutorado em Família na Sociedade Contemporânea) - Programa de Pós-Graduação em Família na Sociedade Contemporânea, Universidade Católica do Salvador, Salvador, 2013. 
introdução; a segunda, explana a fé como vetor na formação de professoras-estudantes; e a terceira seção traz as considerações finais.

\section{A fé como vetor formação de professoras-estudantes}

O estudo que originou esta pesquisa teve como intuito identificar os fatores, os quais influenciavam de maneira positiva e/ou negativa a formação das professorasestudantes. Assim, durante as entrevistas narrativas e mapas dos selves, as colaboradoras do estudo revelaram os sentidos e significados dos diálogos entre a relação de apoio $\leftarrow \rightarrow$ não apoio experienciados durante a formação no PARFOR, os quais emergiram permeados por uma lógica de movimento, dinamismo na interação com o outro, em que a organização e a reorganização dialógica apresentam-se como uma constante. Para Salgado e outros, "todo processo de criação de significado e de construção de existência pessoal pode ser descrito [...] através de um processo contínuo de identificação e reconstrução de si mesmo". ${ }^{7}$ Assim, estes processos só se tornam possíveis através da tensão ininterrupta estabelecida na relação dialógica com o Outro.

Não obstante, a fé, como afirma Segundo, "é uma determinada estrutura de sentido e de valores que cada um constrói para dar significação à sua existência dentro do real". 8 E essa compreensão ecoa no que afirma Teixeira de que "a fé é sobretudo um diálogo que envolve o ser humano com o Mistério maior, um diálogo que envolve amor, reciprocidade e gratuidade. É uma relação de encantamento, um colóquio amoroso" ${ }^{9}$

Neste sentido, os diálogos entre a relação de apoio $\leftarrow \rightarrow$ não apoio tangenciam os movimentos concernentes às contribuições de vozes externas de apoio, como a fé, que as colaboradoras da pesquisa demonstraram através das narrativas que se seguem. Destacase que o apoio sentido através da fé se apresenta como força motriz de vozes interna, as quais as incentivam a continuar na luta contra os obstáculos do cotidiano, além de fornecer audiências com os seus selves com vistas a tomada de decisão em continuar na formação, diante do querer ir a diante. "A Deus! Deus que me dá força. Sempre rezando, todos os dias: 'Ô meu Deus, me dá forças se não eu vou desistir. Eu não vou aguentar não'”. (Professora-estudante Geisa)

Primeiramente em Deus, minha família que me apoia. Por que se não fosse minha família não tinha como eu conseguir chegar onde eu estou. Por que assim, vim de uma família humilde, meus pais são lavradores e hoje eu

7 SALGADO, João et al. Self dialógico: um convite a uma abordagem alternativa ao problema da identidade pessoal. Revista INTERACÇÕES, Portugal, n. 6, p. 8-31, 2007. à p. 16.

8 SEGUNDO, Juan Luis. A história perdida e recuperada de Jesus de Nazaré: dos Sinóticos a Paulo. São Paulo: Paulus, 1997. p. 93.

9 TEIXEIRA, Faustino. João Batista Libânio: a eterna cadência da fé. Revista Perspectiva Teológica, v. 46, n. 128, p. 135-148, jan./abr. $2014 . \quad$ Disponível em: <http://www.faje.edu.br/periodicos/index.php/perspectiva/article/viewFile/2731/2918>. Acesso em: 20 dez. 2017. 
estou onde eu estou, tenho que agradecer a Deus e o esforço se não fosse Ele não tinha chegado onde ia chegar [...] Tem momento que desanima sim. Aí eu paro, vou refletir um pouco e pedir: 'Senhor, me mostra uma luz, não posso desistir!'. Me dá força, aí eu continuo persistindo e seguindo. (Professora-estudante Rita)

A fé apresenta-se como um elemento participante dos processos de analogia de multiplicidade, contradição e polifonia, os quais nada mais são do que um complexo admirável e experimentalmente um meio relevante de compreender como capacidades reflexivas e não reflexivas podem interagir em um self contemporâneo que está constantemente procurando estabelecer a verdade e continuidade, juntamente com outros processos, de inúmeras formas complexas. Com isso, no contexto de um self pluralizado, a necessidade de fé é argumentada como fator persistente na conquista do self-identidade. ${ }^{10}$ Isto fica evidenciado nas narrativas das colaboradoras, quando elas atribuem a Deus a força norteadora para alcançar seu destino identitário através da aquisição da formação, considerando que esta é permeada por vozes internas de desistência e de dificuldades, mas através da fé novas vozes emergem e as vozes de não apoio acabam perdendo força no self.

Em concordância com as observações e argumentos de Adams, Hermans e Hermans-Konopka afirmam que as noções de fé, destino e fatalidade como fenômenos são proeminentes na fase tradicional da história, mas que continuam a desempenhar um importante papel na fase moderna e até pós-moderna. ${ }^{11}$ A combinação de um self tradicional que crê no destino e fatalidade e um self moderno engajado na realização e reflexão do self leva a um self mais complexo, no qual vozes diferentes e até opostas criam contradições e tensões que não são necessariamente problemáticas ou insalubres, mas em vez disso normal e saudável. A fé emanada do self tradicional contribui para um sentimento de continuidade e estabilidade para um self que precisa sobreviver em um período no qual a mudança, fluxo, descontinuidade e incerteza são mais evidentes do que nunca.

Ademais, em conjunto com a fé o apoio do outro é sentido na relação com os sujeitos significativos fora de casa como os professores do PARFOR, colegas, familiares, assim como o incentivo de filhos, esposos e parentes próximos, as quais demonstram apoio relevante e implicam na reconstrução de significados pelas colaboradoras. “Tenho apoio de colegas. Sempre que eu preciso faltar, todo mundo lá na Escola, ajuda é tranquilo [...] compreende? $\mathrm{O}$ meu esposo me ajudou bastante nessa época. Ele ficava com a menina pequena, minha mãe também pegava a minha filha e cuidava". (Professoraestudante Elisete, grifos nossos)

10 ADAMS, M. Whatever will be, will be: Trust, fate and the reflexive self. Culture and Psychology, n. 10, p. 387-408, 2004.

11 HERMANS, H.J.M.; HERMANS-KONOPKA, A. Dialogical Self Theory: positioning and counterPositioning in a globalizing society. Cambrindge: University Press, 2010. 
Alguns professores do PARFOR vêm dando muita força. Alguns que se aproximam e dizem: você não vai desistir! Você tem que conseguir! Você já tá no bom caminho', aí vai dando aquela força.[...] Nós temos professores que realmente tem essa cobrança, quer que você saia dali com uma boa bagagem. Na minha família tem uma tia e uma prima, elas duas são muito importantes, pois quando eu queria desistir elas não deixaram e tentaram me ajudar. Foi relevante essa ajuda! (Professora-estudante Patrícia)

Primeiramente meus pais sempre vêm me apoiando e falando pra mim que eles têm certeza que eu tenho condições de ir adiante, que eu não pare por aí, eles sempre vêm me apoiando. As minhas crianças também, sempre vêm me dando esse apoio. E o companheiro às vezes fala pra mim, que eu já tenho trabalho, o que é que eu quero mais estudando, então é uma coisa assim um pouco complicada. Primeiramente meus pais, meus irmãos e alguns amigos. Eu digo alguns amigos porque eu tenho uma menina que trabalha comigo que me deu o maior apoio para eu não desistisse. Se eu já tinha chegado até ali é porque tinha algo pra me oferecer mais adiante, que eu não desistisse. Eu vim e só tenho que agradecer a ela e a Deus também pela oportunidade. (Professora-estudante Rita)

Importante destacar que essas vozes ecoam como incentivo para continuar, mas as professoras-estudantes reiteram que, além das falas positivas que são efetivadas através de docentes do curso, de colegas, dos filhos, mãe, pai, tia e irmã, um grande incentivo para ser estudante e continuar na profissão consiste na construção de conhecimentos na formação. Ou seja, a motivação interna de que querer ir em frente.

De acordo com a concepção do self abordada por James, enfatiza-se que a existência de diferenças no self não refuta, de maneira alguma, a existência de unidade e continuidade. ${ }^{12}$ Como James assume que o processo de apropriação traz unidade e continuidade ao self, assumimos que o mesmo ato de apropriação cria unidade e continuidade em um self que é espacial e temporariamente "distribuído". Gostaríamos de salientar que, ao conceber o eu como espacial e temporariamente situado, o "eu" não é um "fantasma na máquina",13 mas participa de um processo de posicionamento e reposicionamento.

Neste sentido, o sentimento de conquista e reconhecimento no âmbito do trabalho reverbera nas professoras-estudantes o desejo de resolução das ambiguidades que tangenciam os diálogos entre o apoio $\leftarrow \rightarrow$ não apoio, sobretudo pelo reconhecimento de outrem e da latente solidariedade dos professores da formação no PARFOR, os quais viabilizam a necessidade formativa. Para Valsiner, o tempo é irreversível e é essa compreensão que valida a singularidade das experiências vivenciadas. Nesse sentido,

12 JAMES, William. The principles pf phycology. Londres: Macmillan, 1890.

13 LYSAKER, J. I am not what I seem to be. International Journal for Dialogical Science, 2006. 
ressaltamos que "o futuro é incerto - e o passado está constantemente sendo reconstruído à medida que enfrentamos a incerteza do futuro". ${ }^{14}$

Ressaltar-se que, nesses diálogos, ecoam em duas professoras-estudantes vozes externas que dificultaram inicialmente a internalização das professoras-estudantes no curso de formação no PARFOR, destacando nas narrativas a seguir que "o mais difícil no início foi conseguir tempo para os trabalhos em grupo, leituras, até acostumar foi doido, difícil mesmo, ainda sofro mais já estou acostumando" (Professora-estudante Geisa).

[...] O começo foi muito difícil, sobretudo, na elaboração dos trabalhos acadêmicos. Acho que os professores também não conheciam a nossa realidade, a nossa dificuldade. Tínhamos duas, três, até quatro disciplinas em um final de semana. Eram dois, três, quatro trabalhos, tanto fazia em sala, como levava para casa para fazer. É um curso que exige estudo, ter livros, tem trabalhos para fazer individualmente e em grupo. Você tem que se deslocar de casa, além do trabalho de casa, daqui do PARFOR, tem que fazer trabalho em grupo, então assim é muito puxado! (Professoraestudante Patrícia, grifos nossos)

No contexto da reflexão sobre o processo do self dialógico na educação, Zittoun e Grossen explicitam que é preciso adotar uma visão suficientemente ampla sobre dialogicidade. ${ }^{15}$ Primeiro, tal perspectiva destaca o fato de que toda interação em sala de aula refere-se à situação externa à Instituição, que os estudantes vivenciam em sincronia, mas também que eles experienciaram no seu passado ou como parte de seu futuro. Segundo, isto sugere que elementos culturais ensinados na Instituição ou a serem aprendidos por si mesmos são incorporados em vários processos pessoais, interpessoais e dialógicos sociais. Terceiro, isto enfatiza o fato de que os estudantes como "aprendizes" não podem ser abstraídos dos estudantes como pessoas e que os desafios vivenciados por este último também afetam o anterior. A este respeito, é válido afirmar o possível desenvolvimento funcional dos elementos culturais ensinados na Instituição: a partir de uma perspectiva dialógica, eles não são mais meros objetos de aprendizagem, mais que isso, eles podem introduzir e apoiar uma dinâmica complexa identitária.

É válido destacar ainda que nesse contexto de diálogo é importante explicitar a relação entre os casos de apoio $\leftarrow \rightarrow$ não apoio na continuidade ou não das colaboradoras da pesquisa na formação, como pode ser destacado pelas críticas de colegas de sala, citadas pela professora-estudante Vilara, assim como a ambiguidade entre apoio do pai

14 VALSINER, Jaan. Fundamentos da Psicologia Cultural: mundos da mente, mundos da vida. Porto Alegre: ArtMed, 2012. p. 209.

15 ZITTOUN, Tania; GROSSEN, Michéle. Cultural elements as means of constructing the continuitty of the across various spheres of experience. In: CÉSAR, M.; LIGORIO, B. (Eds.). The interplays between dialogical learning and dialogical self. Charlotte: InfoAge, 2009. 
em detrimento do não apoio da mãe, que é sentido pela professora-estudante Cenilza como força mobilizadora do que realmente ela quer e deseja para a vida. Cenilza apresenta na narrativa uma evidência de que o outro não é ponto determinante do seu querer, revelando o seu sentimento diante da formação no PARFOR. No entanto, sua mãe mostra a reprodução dos silenciamentos dos selves de muitas mulheres que reafirmam na vida os papéis tradicionais de gênero, ou seja, que lugar da mulher é a cuidadora da família. Mas, essa voz da mãe não encontra eco na filha em face da visão do pai que atribui apoio para que ela continue na formação.

O colega fala assim: 'Poxa não gosto de está aqui ouvindo tanta besteira', colegas que criticam o outro, embora isso passe, mas ouvir assim é chato a gente ouvir, tudo bem que possa falar baixinho para o outro, mas para a gente ouvir é chato. Me incomoda o colega tá falando besteira, tem gente que não fala certas coisas por medo da crítica do outro, da crítica. (Professora-estudante Vilara, grifos nossos)

Minha mãe. Aí eu falei pra ela: 'Mainha, casamento nunca foi empecilho na vida de ninguém'. Eu posso dizer isso porque é o que eu sinto. Se ele acha que eu não devo fazer faculdade ele vai ter que procurar uma esposa adequada pra os princípios que ele quer. E painho falou assim pra mim: 'Muito bem minha filha! Sempre sonhei e sempre sabia que você era uma das pessoas que ia me dar esse prazer'. Então assim por um lado eu tenho mainha que pra ela eu tenho que ser família, mulher pra dentro de casa, tomar conta de marido, tomar conta de filho. Já o meu pai que é homem tem a mente mais aberta. A minha relação com meu pai é mais forte do que com mainha. Mas é porque quando eu quero fazer as coisas mainha sempre, ela quer que eu bote um passo pra trás e painho não se eu puder eu boto cem na frente. (Professora-estudante Cenilza, grifos nossos)

Fica registrado nas narrativas das colaboradoras da pesquisa que as vozes de não apoio oportunizam uma autoaudiência com seus selves tangenciando um posicionamento diante dos conflitos e tensões evidenciados por estas vozes, originárias de contextos familiares e acadêmicos, os quais podem se mostrar tanto ratificadores das decisões firmadas pelas professoras-estudantes em face do reconhecimento que a formação apresenta na sua trajetória pessoal e profissional quanto norteadores de posturas diferenciadas diante do outro que gera esta voz, dependendo do que emerge da audiência interna.

Com isso, em determinados momentos tais vozes acabam sendo dominantes, como no caso explicitado por Vilara, onde é gerado um medo à crítica do outro, ou seja, uma retração na participação como discente em sala de aula, ou sobrepostas pelas vozes de apoio, como no caso de Cenilza, onde as vozes de não apoio da mãe são constantemente enfrentadas e acabam sendo pouco referendadas em detrimento das vozes de apoio do pai na sua trajetória. Assim, as relações dialógicas entre os posicionamentos de não apoio evidenciam um constante processo de negociação, cooperação, conflitos e 
consenso levando-as a um movimento contínuo de posicionamento e de reposicionamento.

No entanto, para Hermans e Hermans-Konopka, a voz conflitante pode ser silenciada somente por um tempo, porque ela não pode ser deletada do self inteiramente. Emocionalmente carregada como essa voz é, pode ser tirada do foco, mas não excluída do self para sempre. ${ }^{16}$ A qualquer momento pode se tornar proeminente novamente, dependendo da mudança de situação ou flutuações espontâneas no self. Estes conflitos internos e períodos de instabilidade se tornam menos intensos quando uma dessas vozes se torna mais permanentemente dominante sobre a outra ou quando duas vozes encontram uma base comum de concordância.

\section{Considerações finais}

Tendo como base a fé no processo de formação de professoras-estudantes no PARFOR, não podemos desconsiderar o movimento do self, é oportuno ressaltar que, segundo Valsiner, a noção de self dialógico parte de nosso “imaginário usual sobre diálogos entre pessoas e a transporta para o diálogo intrapsicológico entre 'partes' do self. Não apenas diferentes pessoas se engajam em diálogos, mas todos nós temos nossos próprios diálogos se processando no interior de nossas culturas pessoais". ${ }^{17}$ Essa compreensão de Valsiner sobre o self dialógico nos remete a pensar que as relações dialógicas podem contemplar números variados de partes, as quais podem se posicionar e "coexistir simultaneamente e assegurar estabilidade dinâmica nos fenômenos". ${ }^{18}$ Com isso, é ressalvada dupla importância às dimensões intra e interpsicológicas.

Com efeito, nesta dimensão, no caso das estudantes-professoras entrevistadas nesta pesquisa, é percebido uma forte permeabilidade da posição da fé com o âmbito das posições internas assumidas por elas, de mãe, estudante e esposa, devido à forte relação que este elemento apresenta com a concepção de vida das colaboradoras da pesquisa frente aos obstáculos oferecidos por esta tripla jornada.

Assim, a fé se apresenta como um fator de forte mobilidade e diálogo com as demais relações das estudantes-professoras, podendo assumir uma posição de destaque, visto que se trata de uma fonte de motivação e resiliência diante das dificuldades enfrentadas, sendo influente na construção de vozes que possibilitam audiências do self.

Outrossim, a família incorpora certo incentivo à continuidade das estudantesprofessoras da formação no Curso de Pedagogia encetado no PARFOR diante da fé que compartilham.

16 HERMANS; HERMANS-KONOPKA, 2010.

17 VALSINER, 2012, p. 125.

18 VALSINER, 2012, p. 126. 


\section{Referências}

ADAMS, M. Whatever will be, will be: Trust, fate and the reflexive self. Culture and Psychology, n. 10, p. 387-408, 2004.

AMATUZZI, Mauro M. Fé e Ideologia na Compreensão Psicológica da Pessoa. Psicologia: Reflexão e Crítica, v. 16, n. 3, p. 569-575, 2003.

AMORIM, Ivonete B. Entre casulo e asa: diálogos e movimentos dos selves de professorasestudantes no contexto da formação no PARFOR. Tese (Doutorado em Família na Sociedade Contemporânea) - Programa de Pós-Graduação em Família na Sociedade Contemporânea, Universidade Católica do Salvador, Salvador, 2013.

BRASIL. Coordenação de Aperfeiçoamento de Pessoal de Nível Superior. Plano Nacional de Formação de Professores da Educação Básica - PARFOR. Disponível em:

<http://www.capes.gov.br/educacao-basica/parfor>. Acesso em: 07 dez. 2016.

. Decreto n. 6.755, de 19 de janeiro de 2009. Institui a Política Nacional de Formação dos Profissionais do Magistério e regulamenta a ação da CAPES. Brasília, 2009.

. Ministério da Educação. Lei n. 9.394, de 20 de dezembro de 1996. Estabelece as Diretrizes e Bases da Educação Nacional. Brasília: MEC, 1996.

CHAUDHARY, Nandita; SHARMA, Neerja. Mapping the self and the family. In: ANANDALAKSHAMY, S.; CHAUDHARY, Nandita; SHARMA, Neerja (Orgs.). Researching families and children: culturally appropriate methods. Dehli: Sage, 2008.

HERMANS, H.J.M.; HERMANS-KONOPKA, A. Dialogical Self Theory: positioning and counter-Positioning in a globalizing society. Cambrindge: University Press, 2010.

JAMES, William. The principles pf phycology. Londres: Macmillan, 1890.

LYSAKER, J. I am not what I seem to be. International Journal for Dialogical Science, 2006.

SALGADO, João et al. Self dialógico: um convite a uma abordagem alternativa ao problema da identidade pessoal. Revista INTERACÇÕES, Portugal, n. 6, p. 8-31, 2007.

SEGUNDO, Juan L. A história perdida e recuperada de Jesus de Nazaré: dos Sinóticos a Paulo. São Paulo: Paulus, 1997.

TEIXEIRA, Faustino. João Batista Libânio: a eterna cadência da fé. Revista Perspectiva Teológica, v. 46, n. 128, p. 135-148, jan./abr. 2014. Disponível em:

<http://www.faje.edu.br/periodicos/index.php/perspectiva/article/viewFile/2731/291 8>. Acesso em: 20 dez. 2017.

VALSINER, Jaan. Fundamentos da Psicologia Cultural: mundos da mente, mundos da vida. Porto Alegre: ArtMed, 2012.

ZITTOUN, Tania; GROSSEN, Michéle. Cultural elements as means of constructing the continuitty of the across various spheres of experience. In: CÉSAR, M.; LIGORIO, B. (Eds.). The interplays between dialogical learning and dialogical self. Charlotte: InfoAge, 2009. 